\title{
Briefing: Common laboratory procedures to prepare and cure stabilised soil specimens: a short review
}

1 Wathiq Al-Jabban BSc, MSc, PhD Department of Civil, Environmental and Natural Resources Engineering, Lulea University of Technology, Lulea, Sweden; Department of Civil Engineering, University of Babylon, Hilla, Iraq (Orcid:0000-0003-3474-7340)

2 Jan Laue BSC, MSC, PhD

Department of Civil, Environmental and Natural Resources Engineering, Lulea University of Technology, Lulea, Sweden (Orcid:0000-0003-1935-1743)
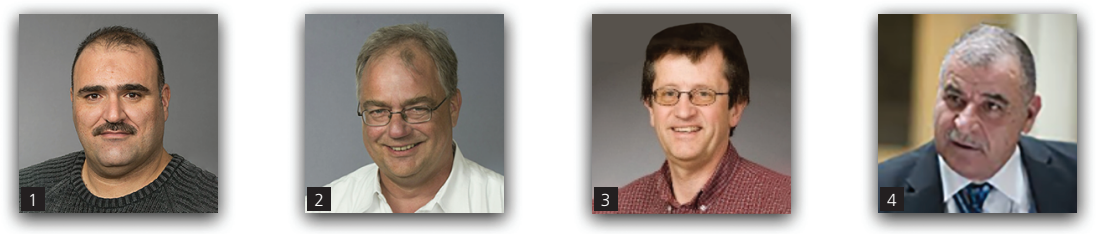

Soil stabilisation is used extensively to improve the physical and mechanical properties of soils to achieve the desired strength and durability properties. During the design process, laboratory investigation is conducted firstly to obtain an enhancement in soil strength and stiffness, in addition to the type and amount of binder required. The methods of preparing and curing specimens of soil-binder mixtures directly influence the properties of the stabilised soils. The most common laboratory protocols used for preparing and curing the specimens of stabilised soil are presented in this short review. The review focuses on several aspects such as homogenisation of the natural soil, mixing type and duration, mould type, moulding techniques and curing time and condition. This review can assist various construction projects that deal with soil improvement to choose an appropriate method for preparing and curing a soil-binder mixture to simulate the field conditions as much as possible and obtain uniform soil-binder mixtures.

\section{Introduction}

For soil stabilisation applications, the specimens of a soil-binder mixture are prepared in a laboratory according to a standard procedure, which in principle should simulate the field conditions. These procedures vary between different countries; in addition, there are variations between different testing companies (Åhnberg and Holm, 2009; BRE, 2002; BSI, 2005; Carlsten and Ekström, 1997; Kitazume, 2012). In Sweden, the specimens of soil-binder mixtures are prepared according to the common procedure described by the Swedish Geotechnical Society (SGS) (Carlsten and Ekström, 1997) and the Building Research Establishment (BRE, 2002). In Japan, the specimens are prepared according to the Japanese Geotechnical Society standard (Kitazume and Terashi, 2013). These variations are related to differences in soil type, type and procedure of soil stabilisation in the field and differences in traditional laboratory testing in general (Åhnberg and Holm, 2009).

Generally, the specimen of a stabilised soil is prepared in a laboratory according to a standard protocol, which normally consists of several steps. Firstly, natural soil is homogenised, and then a cementitious binder is added in dry or in slurry form, and the mixture is blended by hand or an electric blender for a certain time. Then, the soil-binder mixtures are gradually filled as layers in a mould or tube according to the specified technique. Usually, five different moulding techniques can be used or combined to prepare a specimen, as summarised in the following (Kitazume et al., 2015).

- Tapping. For each layer, the mould is tapped (hit) against a table or the floor for a specified number of times until the specimen height is subsequently filled.

- Rodding. For each layer, the mixture is slowly tamped down for a specified number of times using a rod to compact/ smooth out each layer.

- Dynamic compaction. Each layer is compacted by using a Proctor hammer for specified drop height, weight and number of blows to achieve standard compaction energy $\left(600 \mathrm{~kJ} / \mathrm{m}^{3}\right)$ or according to the specified compaction energy.

- Static compaction. Each layer is compressed by using a specified static load for a certain time.

- No compaction. The soil-binder mixture is filled in the mould by either pouring or placing. 


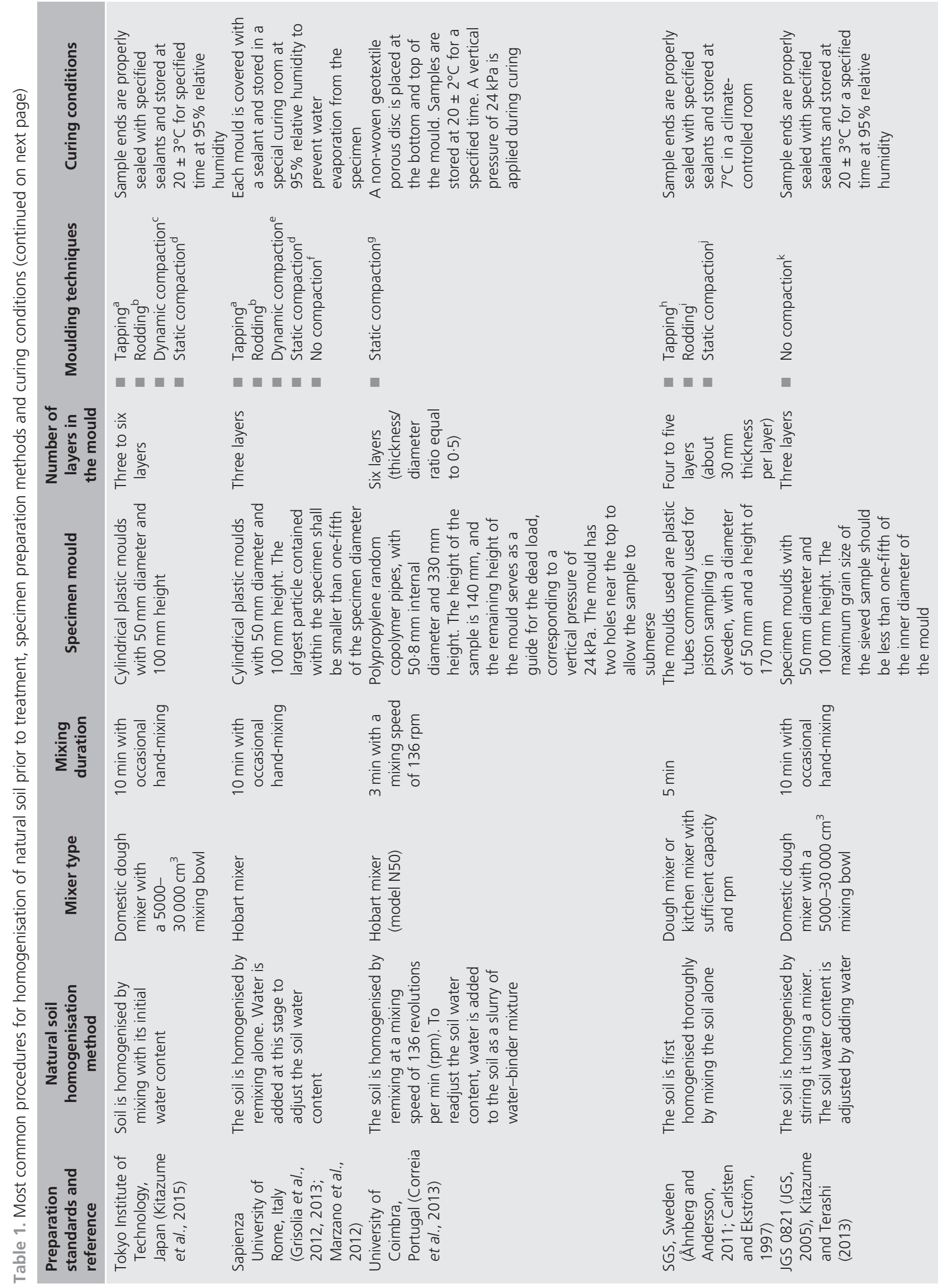




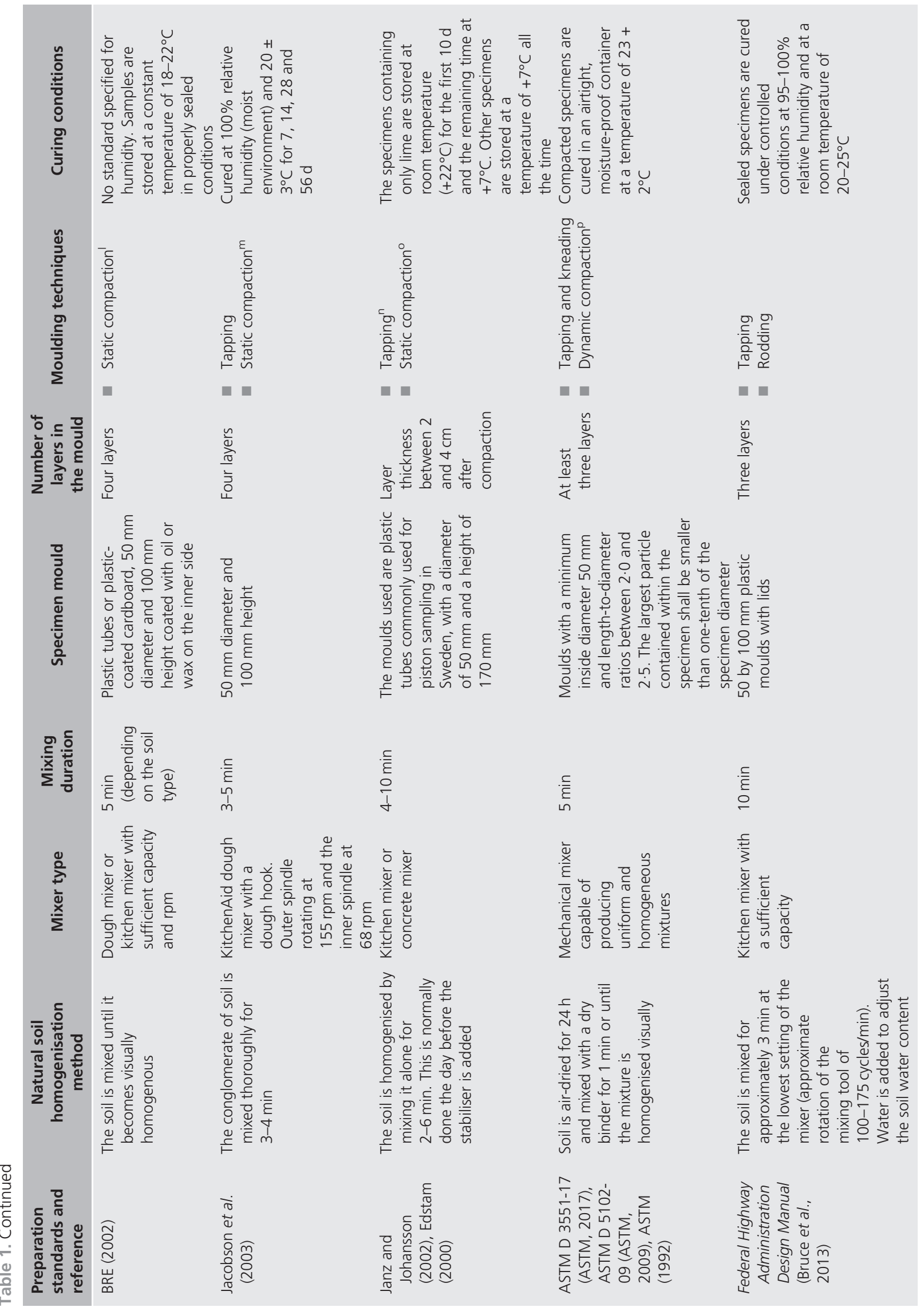




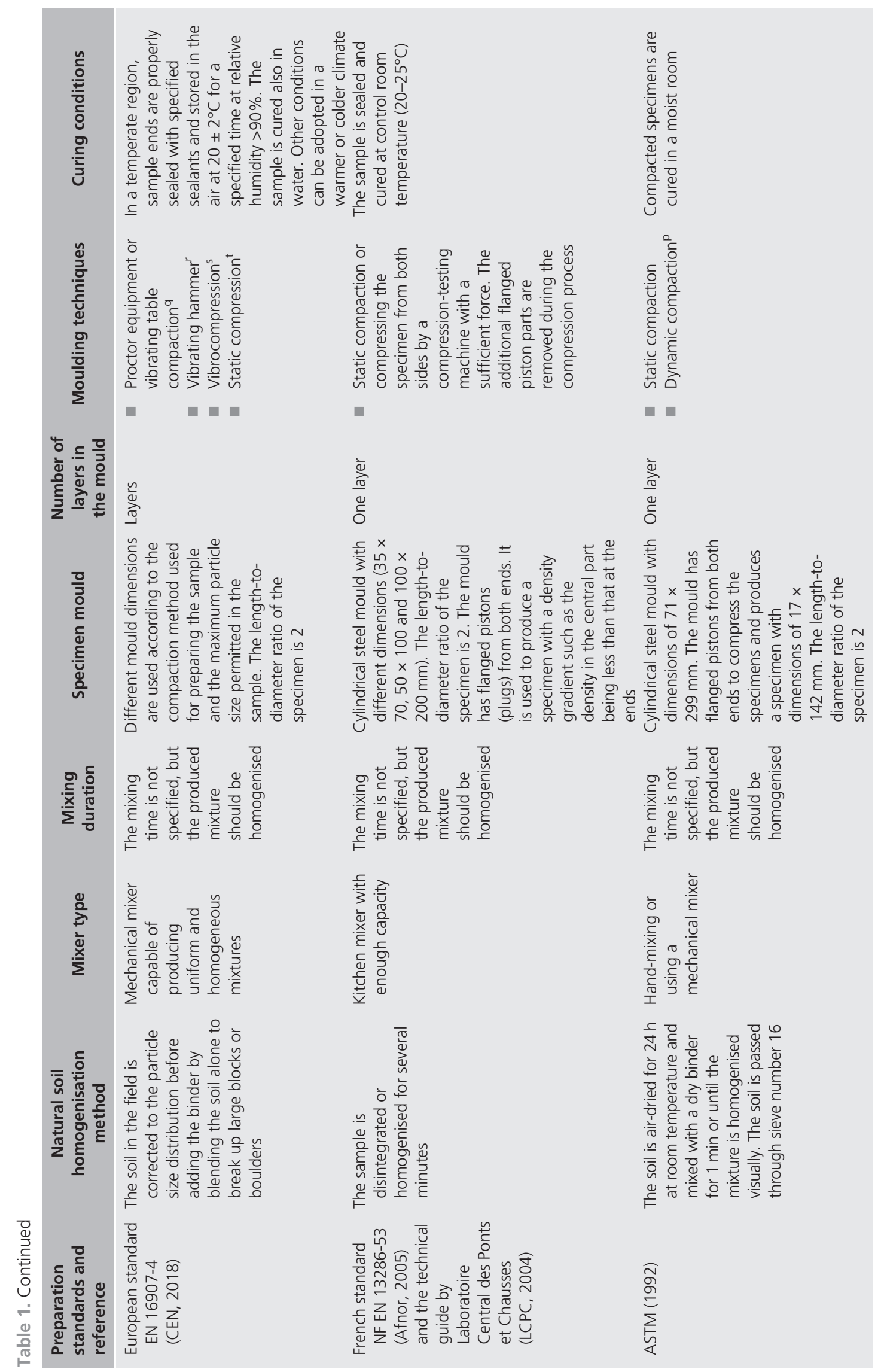



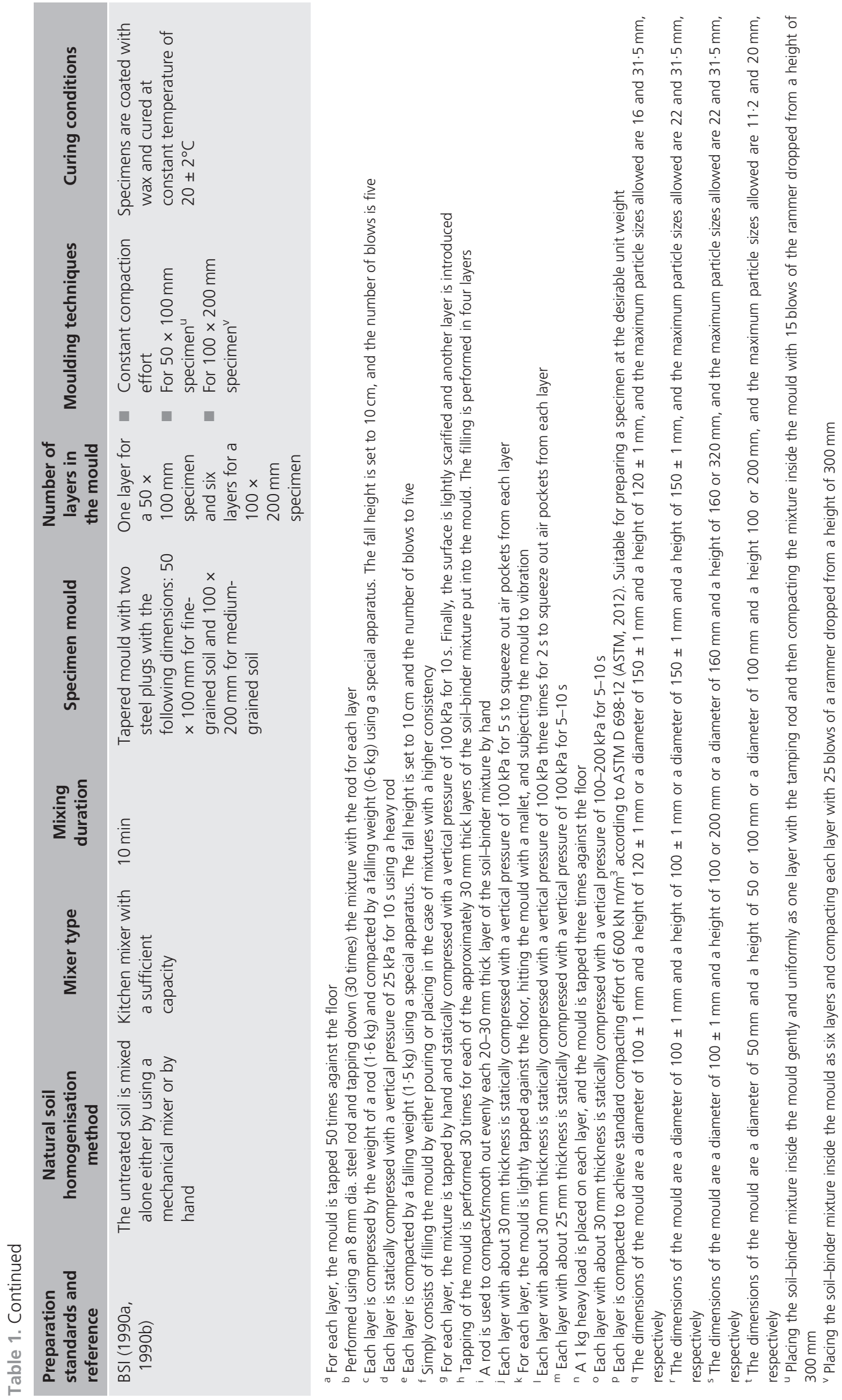
Preparing and homogenising the natural soil before adding the cementitious binders represent the most common concern for obtaining a uniform soil-binder mixture. Disaggregating natural soil prior to treatment has many effects such as homogenising the soil, reducing the variation in water content and obtaining smallersized particles by separating the agglomerated particles. This process could assist in obtaining a uniform distribution of the cementitious binders around soil particles. Table 1 summarises the most common procedures for homogenising natural soil prior to treatment, specimen preparation methods and curing conditions. The most common step in these procedures is that natural soil has to be disaggregated and homogenised by remixing it alone before adding the stabiliser. Most of the standards do not specify the time required for the disintegration and homogenisation process because it can be influenced by several factors, such as the type and gradation, consistency limits, water content and organic content of the soil (Åhnberg and Holm, 2009; Bhadriraju et al., 2007; BRE, 2002; Bruce et al., 2013; Carlsten and Ekström, 1997).

For the effect of mixing time after adding the cementitious binder on the obtained uniform soil-binder mixture, several investigations have shown that the mixing time significantly influences the properties of stabilised soils. Several factors control the uniformity of soil-binder mixtures, such as mixing time, type of mixer used and the characteristics of the original soil, in addition to the type, amount and form of the added binder (in dry or in a slurry form). Kitazume (2005) pointed out the influence of mixing time and form of binder used on the unconfined compressive strength of the stabilised soil. These results were based on the laboratory mixing tests by Nakamura et al. (1982). The laboratory tests were conducted according to the Japanese standards for preparing the laboratory specimens (JGS, 2005) but using different mixing times. Portland cement was added to the soil in either a dry form or a slurry form with a water-to-cement ratio of $100 \%$. The results showed that the unconfined compressive strength of the stabilised soil significantly decreased, as the mixing time was decreased to shorter than $10 \mathrm{~min}$, particularly for the case of when low binder amounts were used. The results also showed that adding the binder in a dry form required a longer mixing time compared with adding the binder in slurry form. The recommended mixing time to mix the soil and binder is set as $10 \mathrm{~min}$ according to Japanese and British standards (BSI, 1990a, 1990b; JGS, 2005). In contrast, in Sweden, the recommended mixing time is set as $5 \mathrm{~min}$ and the produced mixture should be visually homogenised (Åhnberg and Andersson, 2011; Carlsten and Ekström, 1997).

Several investigators have shown that different curing procedures such as curing time and curing temperature significantly influence the strength and stiffness properties of stabilised soils. For the effect of curing time, Kitazume (2005) pointed out the influence of curing time and soil types on the unconfined compressive strength of lime-stabilised soil based on the results from Terashi et al. (1977). The results showed that the strength properties of lime treatment are dependent on the soil type (lime is more effective in clay) and the unconfined compressive strength increases almost linearly with the logarithm of the curing time. For lime treatment, $50-75 \%$ of the final shear strength is obtained after 1-3 months of curing, respectively, while $90 \%$ of stabilised soil shear strength is expected to be obtained after 1 year of curing (Broms, 2004: p. 263). For cement treatment, the improvement in soil strength and stiffness increases as the cement content and curing time increases, and the major improvement in soil strength occurs during the first $28 \mathrm{~d}$ of curing (Hassan, 2009; Ho et al., 2017; Kang et al., 2017; Lorenzo and Bergado, 2006; Sariosseiri and Muhunthan, 2009; Subramaniam et al., 2016). For the effect of curing temperature, Kitazume (2005) mentioned that a higher strength can be obtained under a higher curing temperature during short-term curing, and almost the same impact can be obtained at a longer curing time for different soil-binder treatments.

For soil stabilisation applications, choosing an appropriate laboratory method for preparing and curing the specimens of soil-binder mixtures is considered highly important to simulate the field conditions as much as possible. For instance, in shallow soil stabilisation applications such as road projects where the stabilised soil in the field is usually compacted as layers using a compactor to obtain certain compacting efforts, the dynamic compaction method is the most appropriate laboratory procedure to prepare the soil-binder mixture to simulate the desired compaction efforts. In contrast, for deep soil stabilisation, the compaction efforts are less important compared with those for road projects; therefore, the tapping or static compaction technique can be used. Moreover, choosing the appropriate method also depends on soil type, initial water content and the type and amounts of binder used.

For deep soil stabilisation, a group of researchers studied the influence of different laboratory moulding techniques on the wet density and the unconfined compressive strength of stabilised soil (Kitazume et al., 2015). The study was a part of an international collaboration between four organisations, the Tokyo Institute of Technology, the Sapienza University of Rome, the University of Coimbra and the Swedish Geotechnical Institute. Details of their studies are presented in the first four methods mentioned in Table 1. Regardless of the soil type and the type and amount of binder used, they observed that the modelling technique considerably influenced the wet density and the unconfined compressive strength of stabilised soil. The liquidity index and the undrained shear strength of the soil-binder mixture after treatment were used as indices to evaluate the results. They found that the tapping and rodding techniques were highly applicable when the undrained shear strength was less than $10 \mathrm{kPa}$ or the liquidity index was larger than 1 . The rodding technique was highly applicable when the undrained shear strength ranged from 10 to $20 \mathrm{kPa}$ or the liquidity index ranged between 0.5 and $1 \cdot 0$. Moulding with rodding and dynamic compaction were highly applicable when the undrained shear strength was larger than $20 \mathrm{kPa}$ or the liquidity index was smaller than $0 \cdot 5$. 


\section{Conclusions}

This short review presents the most common laboratory procedures used to prepare and cure the specimens of soil-binder mixtures. The aspects of the various laboratory procedures presented include homogenisation of the natural soil, blending time, mould types and moulding techniques and curing conditions (time and temperature). Different moulding techniques and curing conditions considerably influence the properties of the soil-binder mixture. For soil stabilisation applications, choosing the appropriate method for preparing and curing the specimens of soil-binder mixtures is considered highly important to simulate the field conditions as much as possible, which subsequently reflect the strength and stiffness of stabilised soil in the field site. Dynamic compaction and rodding methods are more applicable for shallow soil stabilisation such as road projects or when the soil shear strength is greater than $20 \mathrm{kPa}$. Static compaction and tapping methods are more applicable for deep soil stabilisation or when the soil shear strength is lower than $10 \mathrm{kPa}$.

\section{Acknowledgements}

The authors would like to acknowledge the Iraqi Ministry of Higher Education and Scientific Research and the University of Babylon for offering the opportunity to pursue this study through their financial support.

\section{REFERENCES}

Afnor (Association Française de Normalisation) (2005) NF EN 13286-53: Unbound and hydraulically bound mixtures. Methods for the manufacture of test specimens of hydraulically bound mixtures using axial compression. Afnor, Paris, France.

Åhnberg H and Andersson G (2011) SGI Laboratory Tests - Influence of Molding Technique: International Collaborative Study on Deep Mixing Method. SGI14187/14598. Swedish Geotechnical Institute, Stockholm, Sweden.

Åhnberg H and Holm G (2009) Influence of laboratory procedures on properties of stabilized soil specimens. Proceedings of the 2009 International Symposium on Deep Mixing and Admixture Stabilization, Okinawa, Japan.

ASTM (1992) ASTM Standards on Soil Stabilization with Admixtures, 2nd edn. ASTM International West Conshohocken, PA, USA.

ASTM (2009) D 5102-09: Standard test method for unconfined compressive strength of compacted soil-lime mixtures. ASTM International, West Conshohocken, PA, USA.

ASTM (2012) D 698-12: Standard test methods for laboratory compaction characteristics of soil using standard effort $\left(12400 \mathrm{ft}-\mathrm{lbf} / \mathrm{ft}^{3}(600 \mathrm{kN}-\mathrm{m} /\right.$ $\left.\mathrm{m}^{3}\right)$ ). ASTM International, West Conshohocken, PA, USA.

ASTM (2017) D 3551-17: Standard practice for laboratory preparation of soil-lime mixtures using mechanical mixer. ASTM International, West Conshohocken, PA, USA.

Bhadriraju V, Puppala AJ, Madhyannapu RS and Williammee R (2007) Laboratory procedure to obtain well-mixed soil binder samples of medium stiff to stiff expansive clayey soil for deep soil mixing simulation. Geotechnical Testing Journal 31(3): 225-238, https://doi. org/10.1520/GTJ100936.

BRE (Building Research Establishment) (2002) Design Guide: Soft Soil Stabilisation - EuroSoilStab: Development of Design and Construction Methods to Stabilize Soft Organic Soils. IHS BRE Press, London, UK, CT97-0351.

Broms BB (2004) Lime and lime/cement columns. In Ground Improvement, 2nd edn. (Moseley MP and Kirsch K (eds)). Spon Press, Abingdon, UK, pp. 252-330.
Bruce MEC, Berg RR, Collin JG et al. (2013) Federal Highway Administration Design Manual: Deep Mixing for Embankment and Foundation Support. Offices of Research and Development, Federal Highway Administration, Washington, DC, USA, Report No. FHWA-HRT-13-046.

BSI (1990a) BS 1924-1:1990: Stabilized materials for civil engineering purposes. General requirements, sampling, sample preparation and tests on materials before stabilization. BSI, London, UK.

BSI (1990b) BS 1924-2:1990: Stabilized materials for civil engineering purposes. Methods of test for cement-stabilized and lime-stabilized materials. BSI, London, UK.

BSI (2005) BS EN 14679:2005: Execution of special geotechnical works. Deep mixing. BSI, London, UK.

Carlsten P and Ekström JE (1997) Lime and Lime Cement Columns: Guide for Project Planning, Construction and Inspection. Swedish Geotechnical Society, Linköping, Sweden, Report 4:95E.

CEN (European Committee for Standardization) (2018) EN 16907 4:2018: Earthworks. Soil treatment with lime and/or hydraulic binders. CEN, Brussels, Belgium.

Correia AAS, Venda Oliveira PJ and Lemos LJ (2013) Prediction of the unconfined compressive strength in soft soil chemically stabilized. Proceedings of the 18th International Conference on Soil Mechanics and Geotechnical Engineering, Paris, France, pp. 2457-2460.

Edstam T (2000) Laboratorieinblandning för Stabilisering av Lera Referensmetod. Swedish Deep Stabilization Research Centre, Linköping, Sweden, Arbetsrapport 16 (in Swedish).

Grisolia M, Kitazume M, Leder E, Marzano IP and Morikawa Y (2012) Laboratory study on the applicability of molding procedures for the preparation of cement stabilized specimens. Proceedings of the International Symposium on Recent Research, Advances and Execution Aspects of Ground Improvement Works, Brussels, Belgium, pp. 335-343.

Grisolia M, Leder E and Marzano IP (2013) Standardization of the molding procedures for stabilized soil specimens as used for QC/QA in deep mixing application. Proceedings of the 18th International Conference on Soil Mechanics and Geotechnical Engineering, Paris, France, pp. 2481-2484.

Hassan M (2009) Engineering Characteristics of Cement Stabilized Soft Finnish Clay - a Laboratory Study. Licentiate's thesis, Helsinki University of Technology, Helsinki, Finland.

Ho LS, Nakarai K, Ogawa Y, Sasaki T and Morioka M (2017) Strength development of cement-treated soils: effects of water content, carbonation, and pozzolanic reaction under drying curing condition. Construction and Building Materials 134: 703-712, https://doi.org/10. 1016/j.conbuildmat.2016.12.065.

Jacobson JR, Filz GM and Mitchell JK (2003) Factors Affecting Strength Gain in Lime-Cement Columns and Development of a Laboratory Testing Procedure. Virginia Center for Transportation Innovation and Research, Charlottesville, VA, USA.

Janz M and Johansson SE (2002) The Function of Different Binding Agents in Deep Stabilization. Swedish Deep Stabilization Research Centre, Linköping, Sweden, Report 9.

JGS (Japanese Geotechnical Society) (2005) Japanese Geotechnical Society standard 'Practice for making and curing stabilized soil specimens without compaction' (JGS 0821). Proceedings of the 2005 International Conference on Deep Mixing, Best Practice and Recent Advances. Swedish Geotechnical Society, Stockholm, Sweden, vol. 2, report 13 , pp. $816-835$.

Kang GO, Tsuchida T and Kim YS (2017) Strength and stiffness of cementtreated marine dredged clay at various curing stages. Construction and Building Materials 132: 71-84, https://doi.org/10.1016/j.conbuildmat. 2016.11.124.

Kitazume M (2005) State of practice report - field and laboratory investigations, properties of binders and stabilized soil. In Deep Mixing (Rydell B, Westberg G and Massarsch KR (eds)). Swedish 
Geotechnical Research

Volume 7 Issue 1
Briefing: Common laboratory procedures

to prepare and cure stabilised soil

specimens: a short review

Al-Jabban, Laue, Knutsson and Al-Ansari
Deep Stabilization Research Centre, Stockholm, Sweden, vol. 2, pp. 660-684.

Kitazume M (2012) Influence of specimen preparation on unconfined compressive strength of cement-stabilized kaolin clay. Proceedings of the International Symposium on Recent Research, Advances and Execution Aspects of Ground Improvement Works, Brussels, Belgium, vol. 2, pp. 385-393.

Kitazume M and Terashi M (2013) The Deep Mixing Method. CRC Press, Boca Raton, FL, USA.

Kitazume M, Grisolia M, Leder E et al. (2015) Applicability of molding procedures in laboratory mix tests for quality control and assurance of the deep mixing method. Soils and Foundations 55(4): 761-777, https://doi.org/10.1016/j.sandf.2015.06.009.

LCPC (Laboratoire Central des Ponts et Chausses) (2004) Soil Treatment with Limé and/or Hydraulic Binders: Application to the Construction of Fills and Capping Layers. LCPC, Paris, France.

Lorenzo GA and Bergado DT (2006) Fundamental characteristics of cement-admixed clay in deep mixing. Journal of Materials in Civil Engineering 18(2): 161-174, https://doi.org/10.1061/(ASCE)08991561(2006)18:2(161).
Marzano IP, Leder E, Grisolia M and Danisi C (2012) Laboratory study on the molding techniques for QC/QA process of a deep mixing work. Proceedings of the 3rd International Conference on New Developments in Soil Mechanics and Geotechnical Engineering, Nicosia, North Cyprus.

Nakamura M, Matsuzawa S and Matsushita M (1982) Study of the agitation mixing of improvement agents. Proceedings of the 17th Japan National Conference on Soil Mechanics and Foundation Engineering, Nara, Japan, vol. 2, pp. 2585-2588 (in Japanese). Sariosseiri F and Muhunthan B (2009) Effect of cement treatment on geotechnical properties of some Washington State soils. Engineering Geology 104(1-2): 119-125, https://doi.org/10.1016/j.enggeo.2008.09. 003.

Subramaniam P, Sreenadh MM and Banerjee S (2016) Critical state parameters of dredged Chennai marine clay treated with low cement content. Marine Georesources \& Geotechnology 34(7): 603-616, https://doi.org/10.1080/1064119X.2015.1053641.

Terashi M, Okumura T and Mitsumoto T (1977) Fundamental properties of lime treated soil (1st report). Report of the Port and Harbour Research Institute 16(1): 3-28 (in Japanese).

\section{How can you contribute?}

To discuss this paper, please submit up to 500 words to the editor at journals@ice.org.uk. Your contribution will be forwarded to the author(s) for a reply and, if considered appropriate by the editorial board, it will be published as a discussion in a future issue of the journal. 